\title{
CONCEPÇÕES DE LINGUAGEM E AVALIAÇÃO DO ALUNO \\ COM DIAGNÓSTICO DE DEFICIÊNCIA INTELECTUAL
}

\section{Catia de Azevedo Fronza}

Universidade do Vale do Rio dos Sinos

\section{Cassiano Ricardo Haag}

Universidade do Vale do Rio dos Sinos

\section{Andréia Gulielmin Didó}

Escola Especial para Surdos Frei Pacífico

\section{Resumo}

Neste artigo, trazemos discussões sobre a avaliação na escola, voltando-nos ao que temos chamado de contexto de diferenças. Inicialmente, compartilhamos reflexões acerca da avaliação no processo de ensinoaprendizagem, apontamentos sobre concepções de avaliação e algumas de suas consequências. Dando continuidade ao texto, propomos uma discussão sobre a avaliação do indivíduo com suspeita e/ou diagnóstico de deficiência intelectual. Essa discussão traz a avaliação da deficiência intelectual a partir da definição postulada pela American Association on Intellectual and Developmental Disabilities (AAIDD), problematizando-a no sentido de compreender de que maneira a concepção de linguagem interfere na reflexão sobre a definição de deficiência intelectual. Por meio dessas ponderações, colocamos algumas de nossas inquietações e perspectivas, cientes de que há muito mais a discutir sobre o contexto de diferenças e a avaliação nesse cotidiano escolar.

Palavras-chave: Avaliação; Linguagem; Deficiência intelectual.

Olh@res, Guarulhos, v. 2, n. 1, p. 194-221. Maio, 2014. 


\title{
CONCEPTIONS OF LANGUAGE AND STUDENT ASSESSMENT WITH A A DIAGNOSIS OF INTELLECTUAL DISABILITY
}

\begin{abstract}
In this article, we approach issues about the assessment in school, privileging what we have called "context of differences". Firstly, we share thoughts regarding the assessment in the teaching-learning process, notes on conceptions of assessment, and its consequences. In the following part, we bring the discussion about evaluation of the individual suspected and/or diagnosed as having intellectual disability from the definition postulated by American Association on Intellectual and Developmental Disabilities (AAIDD), problematizing it to comprehend by which manner the conception of language interferes with the definition of intellectual disability. Through these ponderings, we introduce some of our restlessness and perspectives, but we are aware that there is much more to be discussed about the context of differences and the evaluation in the school routine.
\end{abstract}

Key words: Assessment; Language; Intellectual disability. 


\section{Introdução}

Podemos afirmar que, atualmente, a realidade escolar não é a idealizada por pais e educadores. Questões como currículo, disciplina, inclusão/exclusão, avaliação e outras tantas estão sempre presentes em reuniões de professores, de pais ou nos corredores das escolas. Concepções e metodologias são discutidas e avaliadas constantemente no meio educacional, a fim de contribuir para a construção e a transmissão de saberes para a sociedade. Essas discussões não devem se limitar à busca de receitas prontas para resolver problemas do cotidiano de alunos e de professores, mas aprofundar e problematizar entendimentos acerca de tais questões.

Em meio a esse cenário, a avaliação é parte do importante processo de ensino-aprendizagem em língua materna. Enfim, discutir acerca da avaliação possibilita, entre outras reflexões, contribuir para a busca de um ensino que atenda às necessidades dos alunos, permitindo que o professor repense suas concepções de ensino e suas práticas. Os métodos avaliativos sustentam a lógica do trabalho escolar, ocupando um espaço importante no processo de aprendizagem e determinante para o avanço ou a retenção do aluno.

Nesse contexto, ao se discutir a avaliação e mesmo a definição de deficiência intelectual, deve-se estabelecer com clareza a concepção de linguagem que está na origem dessas reflexões. Ao tratar da linguagem, é comum encontrar autores que implícita ou explicitamente expressam posicionamentos entusiasmados como este: "Critchley, em 1975, foi muito feliz na conceituação da linguagem ao expor de forma clara e simples que 'linguagem é a expressão e a recepção de ideias e sentimentos" (PEDROSO \& ROTTA, 2006, p. 131). A concepção de que a linguagem é "um instrumento de transmissão de informações" (ALVAREZ et al., 2008, p. 136) é uma constante nas obras que servem de base para os profissionais que avaliam e/ou prestam apoios a pessoas com suspeita ou diagnóstico de

Olh@res, Guarulhos, v. 2, n. 1, p. 194-221. Maio, 2014. 
deficiência intelectual ${ }^{1}$. É comum ainda essa concepção se misturar com visões ainda mais mentalistas ou mesmo, num outro extremo, a visões socioculturais ou interacionistas.

A avaliação é uma tarefa complexa e não deve ser vista como uma atividade simplesmente técnica. Avaliar a aprendizagem de um aluno requer olhar além do certo e do errado; envolve respeitar o sujeito, sua cultura, suas experiências. Nesse sentido, temos interpretado a deficiência intelectual como uma característica de desenvolvimento específica que atribui um déficit cognitivo ao sujeito em razão de este se manifestar na e pela linguagem de modo divergente ao padrão esperado. Em outras palavras, as manifestações de linguagem da pessoa com diagnóstico de deficiência intelectual apontam para uma outra intelectualidade, diversa da esperada como ideal pela cultura e, nesse sentido, gera um desajuste entre o sujeito e o meio. Portanto, temos tentado evidenciar que o que é diverso tradicionalmente tem sido lido como limitado, sendo tratadas características que deveriam estar em paralelo por meio de uma metáfora de escalas verticalizadas.

É necessário que, ao avaliar, o professor tenha uma postura ética e sensata, com critérios claros. E, a partir dos resultados alcançados, será capaz de traçar estratégias que possibilitem rever suas práticas e, se necessário, modificá-las. Assim, se, para um especialista em linguagem, é suficientemente complexo compreender as manifestações dos sujeitos pesquisados, mesmo ele tendo razoável clareza da concepção de linguagem que o orienta, vale dar maior atenção às concepções de linguagem que balizam os trabalhos sobre a avaliação da pessoa com suspeita ou diagnóstico de deficiência intelectual, a fim de fornecer elementos coerentes

\footnotetext{
${ }^{1}$ Neste trabalho, ao utilizarmos a expressão "pessoa com suspeita de deficiência intelectual", referimo-nos a indivíduos que estão em processo de avaliação (ressaltando que esse processo deve ser realizado por uma equipe multidisciplinar que pode incluir psicólogo, psicopedagogo, neuropediatra, fonoaudiólogo, entre outros profissionais), assim como vamos empregar a expressão "pessoa com diagnóstico de deficiência intelectual" quando nos remetermos a pessoas com o processo diagnóstico concluído. Com isso, evitaremos o uso da expressão "pessoa com deficiência intelectual".
}

Olh@res, Guarulhos, v. 2, n. 1, p. 194-221. Maio, 2014. 
para compreender esse fenômeno. Uma abordagem que não consegue definir claramente a qual concepção se filia dá margem para os profissionais caírem na malha de preconceitos e do senso comum ao lidar com os problemas de linguagem.

Assumindo tais premissas, nas seções que seguem, trazemos um breve panorama sobre diferentes concepções de avaliação e partilhamos discussões acerca da concepção de linguagem que permeia o cotidiano escolar do qual participam pessoas com diagnóstico ou suspeita de deficiência intelectual.

\section{Sobre concepções avaliativas ${ }^{2}$}

Avaliar pressupõe clareza e conhecimento por parte do professor acerca das funções da avaliação, das técnicas avaliativas, dos procedimentos e dos critérios. É necessário pensar a avaliação, enfatizando aspectos que, além de refletirem sobre o processo, viabilizem técnicas avaliativas, aperfeiçoem métodos, estratégias e materiais que possibilitem resultados esperados tanto para o professor como para o aluno. Com esse intuito, lançaremos nosso olhar sobre tipos e concepções avaliativas.

Embora haja um consenso entre autores sobre a diversidade de conceitos que permeiam a avaliação na escola, Hoffmann (1996), Vasconcellos (2000) e Luckesi (2005), entre outros, colocam a avaliação como um dispositivo de mediação capaz de orientar o professor no processo de ensinoaprendizagem, assim como suas práticas e intervenções em sala de aula, e o aluno, a compreender seu próprio processo de aprendizagem.

A Lei de Diretrizes e Bases da Educação Nacional (LDBEN 9394/96) reitera a avaliação escolar como um processo mais amplo, processual e contínuo. O processo de avaliação, independentemente do método utilizado, acontece em todas as escolas, exercendo controle e vigilância sobre os

\footnotetext{
${ }^{2}$ Esta seção parte das considerações apresentadas por Didó (2012).
}

Olh@res, Guarulhos, v. 2, n. 1, p. 194-221. Maio, 2014. 
sujeitos escolares, permitindo normalizar e controlar esses sujeitos. Ao conferir valor ou qualidade e medir a aprendizagem do aluno, fazem-se avaliações que imprimem marcas nos sujeitos e os posicionam em lugares de inclusão e exclusão.

Hoffmann (1996) destaca que as práticas avaliativas classificam e sentenciam, mas faz a ressalva de que tais práticas deveriam ser problematizadas, visando ao questionamento e à reflexão sobre a ação, uma avaliação mediadora. Esta tem como significado fundamental conhecer e prestar atenção no aluno, ouvir seus argumentos, deixar que expresse suas ideias, propor novas e desafiadoras questões, desencadear momentos de discussões entre os pares, oferecer oportunidades para que explorem ocasiões de desenvolvimento, buscando uma educação voltada à construção de seu conhecimento.

Podemos ainda fazer menção às funções da avaliação, as quais, segundo Bloom et al. (1993), podem ser de três tipos: i) diagnóstica ou analítica, ii) formativa e iii) somativa.

$\mathrm{Na}$ avaliação com função diagnóstica ou analítica, o professor verifica o conhecimento prévio dos alunos, a fim de, baseado nos saberes que o aluno já possui, preparar as atividades que proporcionarão novos saberes. Assim, será mais fácil planejar, determinar quais competências trabalhar durante o ano e qual conteúdo. A avaliação diagnóstica é uma ferramenta que deverá estar de acordo com os conteúdos e objetivos de cada série ou ciclo, permitindo eficácia no processo de ensino-aprendizagem. Na avaliação diagnóstica, portanto, devem-se alcançar três objetivos: identificar o ponto de partida do aluno; verificar se a aprendizagem está ocorrendo; e, ao perceber possíveis problemas, possibilitar ao aluno solucioná-los no curso do ano letivo.

A avaliação formativa, conforme Bloom et al. (1993), é entendida como controladora, pois verifica, ao longo do ano letivo, em que medida o aluno atinge os objetivos propostos. É uma avaliação orientadora, na qual o

Olh@res, Guarulhos, v. 2, n. 1, p. 194-221. Maio, 2014. 
discente é informado sobre seus erros e acertos; e motivadora, pois evita o estresse causado pelas avaliações, permite que o professor identifique as dificuldades de ensino-aprendizagem, além de contribuir para repensar sua prática, desde que saiba o que quer avaliar e com qual finalidade.

A última função apresentada por Bloom et al. (1993) é a avaliação somativa, cujo papel é verificar o domínio do aluno em uma área de aprendizagem e classificá-lo conforme o nível de aproveitamento do semestre ou do ano em uma única prova, de acordo com os objetivos previamente estipulados.

Independentemente do tipo de avaliação realizada, estaremos sempre lidando com uma forma de medida. A forma de constituir a avaliação é diferente; toda avaliação, contudo, parte de uma norma, na tentativa de enquadrar o normal e o anormal. De acordo com o grupo ou com o indivíduo é definido o que é normal ou alvo a ser alcançado e, depois, é verificado seu rendimento. Seja qual for o registro utilizado para indicar como tal rendimento é percebido, no parecer descritivo, por exemplo, ou de modo processual ou numérico, avaliar é sempre uma maneira de medir. Cabe destacar que os critérios de avaliação de desempenho no âmbito escolar vêm sendo questionados por especialistas, como Vasconcellos (1992), Luckesi (2005), entre outros autores.

Outro aspecto que merece discussão volta-se às diferenças entre avaliação e correção. Luckesi (2005), por exemplo, diferencia "examinação" de "avaliação". Para o autor, de maneira geral, as escolas não avaliam seus alunos, realizam exames e não avaliações. Em um primeiro momento, para um leitor desavisado, ambos os instrumentos de avaliação de desempenho são semelhantes, mas possuem diferenças cruciais. Os exames, como destaca Luckesi (2005), focam-se no desempenho final do aluno, desconsiderando seu ponto inicial; as provas são pontuais, pois se preocupam com o conhecimento do aluno somente no ato de seu exame. Além disso, os exames são classificatórios, seletivos e excludentes: classificatórios, por identificarem os alunos em aprovados ou reprovados, e

Olh@res, Guarulhos, v. 2, n. 1, p. 194-221. Maio, 2014. 
seletivos ou excludentes, na medida em que os não classificados não avançam no sistema escolar.

Para Luckesi (2005), a avaliação possui características opostas às do exame. A avaliação é não pontual, pois tudo o que acontece ao longo do processo de avaliação, tanto anteriormente como os desdobramentos futuros, é pertinente. A avaliação é diagnóstica, quando não interessa classificar o aluno em aprovado ou reprovado; o importante é que ele efetivamente aprenda. Além disso, o autor sustenta que a avaliação é inclusiva, à medida que busca não excluir os participantes do processo de aprendizagem. Luckesi (2005) esclarece que, no processo de análise do conhecimento nas escolas, o aluno somente "sofre a ação" de ser avaliado, como um expectador ou paciente desse processo avaliativo: não participa efetivamente do seu próprio processo de aprendizagem, aguarda a opinião sobre sua tarefa, sem interferir, partilhar ou questionar. $\mathrm{O}$ autor destaca ainda a importância da autoavaliação no processo de construção de conhecimento dos alunos, pois contribui para o desenvolvimento do ser humano em geral, não somente do aluno; uma pessoa com autocrítica é capaz de refletir sobre suas ações e repensá-las, mudar de posição ou certificar-se da escolha ou do caminho a ser percorrido. A avaliação faz parte de um ritual pré-determinado; se não houver apropriação por parte do aluno, pode ser transformada em um processo que mensura, classifica e exclui. O professor que não tem definidos quais objetivos pretende alcançar, conforme Luckesi (2005), utiliza a avaliação como instrumento de poder, que faz o aluno silenciar ou cumprir tarefas, ou, ainda, emprega a avaliação para cobrar conteúdos sem significado. Neste caso, o docente utiliza a avaliação com função classificatória, simplesmente para aprovar, reprovar ou determinar quem é quieto, interessado, inquieto, desinteressado, bom ou ruim. Em consequência, tais atitudes refletem a face da escola que contribui para a exclusão.

Olh@res, Guarulhos, v. 2, n. 1, p. 194-221. Maio, 2014. 
Concordamos com Luckesi (2005) quando diz que esse tipo de avaliação em nada contribui para o crescimento do aluno e do professor, pois se trata de um instrumento que emperra o processo educativo. Vasconcelos (2000), por sua vez, destaca que o professor precisa refletir sobre sua prática para conseguir mudar o modo de avaliar. Ressaltamos também que os instrumentos de avaliação devem ser educativos, interligados às concepções de ensino-aprendizagem do educador, exigindo uma postura profissional crítica em avaliação, uma vez que, ao avaliar o aluno, o professor, consequentemente, tem subsídios para avaliar seu trabalho.

O significado da avaliação, conforme Vasconcelos (2000), não deve ter a pretensão de padronizar o comportamento do aluno, mas deve ter como meta criar oportunidades de desenvolvimento e aprendizagem, permitindo que o aluno se manifeste criticamente, participando das transformações da sociedade. Como recomenda Vasconcelos (2000), a avaliação deve ser vista como um procedimento constante na construção e na produção de conhecimento do aluno e não como um momento único característico da prova.

Sabemos que as práticas pedagógicas contribuem diretamente para o desenvolvimento do aluno. Podemos refletir sobre o olhar do professor que, dependendo da sua concepção, apenas corrige, apenas avalia ou corrige e avalia. $\mathrm{O}$ docente precisa ter consciência do que ele quer avaliar e utilizar a ferramenta adequada para isso, uma vez que a avaliação é um imperativo escolar. Apenas corrigindo, leva em conta as respostas dadas e procura o erro, pois seu olhar está voltado para o que o aluno fez de errado. Infelizmente, este pensamento parece dominar na atitude do professor. $\mathrm{O}$ docente que avalia atribui uma nota de acordo com o que considera correto, muitas vezes por ter muitas turmas ou por estas serem numerosas, não faz anotações e não discute com os alunos, que, por sua vez, não entendem o porquê dos registros avaliativos e ficam insatisfeitos. O professor que corrige e avalia, por sua vez, dá um diagnóstico, entende seu aluno como sujeito de sua aprendizagem, percebe a aprendizagem como ação e reflexão,

Olh@res, Guarulhos, v. 2, n. 1, p. 194-221. Maio, 2014. 
estabelece critérios e objetivos, encontra procedimentos que deixem claro ao aluno o quanto ele contribuiu para o processo de ensino e de aprendizagem. Aluno e professor interagem, portanto, a todo momento.

É urgente a participação mais efetiva de todos os envolvidos nesse processo, a fim de implementar projetos educativos que visem a uma prática de ensino eficaz e enriquecedora, que proporcione a troca de conhecimento entre aluno-professor-aluno, compreendendo e respeitando as diferenças no contexto escolar e fora deste. É importante compreender que avaliar, além de ser um procedimento complexo, requer compromisso de todo o sistema escolar, dos professores, dos alunos, da comunidade escolar; não pode ser unilateral. É necessária uma cumplicidade que vai além de ensinar e aprender.

A avaliação, como já ressaltamos, deve permitir compreender os níveis de aprendizagem em que os alunos se encontram, para, assim, focar práticas que contribuam para preencher as lacunas existentes, na busca de melhores resultados. O papel da escola, como vemos, vai além do processo de formação de alunos e professores. As práticas tradicionais há muito estão aprisionadas a metodologias fragmentadas e descontextualizadas. Cabe ressaltar que verdades absolutas, práticas pedagógicas engessadas nas quais prevalece a simples transmissão de conhecimentos precisam perder espaço. O foco deve estar no educando e não mais no professor.

Precisamos esclarecer, contudo, que refletir sobre as concepções de avaliação não significa condenar ou criticar as práticas pedagógicas ou escolares, mas ressaltar a possibilidade de outras práticas e caminhos para uma avaliação coerente que reflita também sobre as concepções de linguagem presentes na escola e assumidas pelos professores.

Considerando tais ponderações, é possível perceber que, através dos tempos e das concepções, em diversos momentos da história da educação no Brasil, avaliar tem se limitado à realização de uma prova oral ou escrita, enfatizando o poder absoluto do professor que, por meio da nota ou de registros mais detalhados, determina o que o aluno sabe. Atualmente, ainda

Olh@res, Guarulhos, v. 2, n. 1, p. 194-221. Maio, 2014. 
verificamos que, na avaliação da aprendizagem escolar, realizada conforme o interesse do professor ou do sistema de ensino, o conteúdo ensinado nem sempre é levado em consideração. Ao mesmo tempo, observamos que se desenha uma relação de interação entre professor-aluno. Felizmente, abre-se mais espaço para essa parceria, promovendo um estreitamento desta relação. Após essas considerações, reforçamos a necessidade de tais discussões. Estamos cientes de que as formas de avaliar diferem entre si, mas, se combinadas, podem contribuir para o ensino-aprendizagem, pois todas pretendem atingir a eficiência da avaliação, ou seja, possibilitar a formação efetiva do aluno. Conhecendo dúvidas, inquietações e dificuldades do aluno, o professor tem subsídios para repensar sua prática e superar fatores que interferem na aprendizagem, levando o aluno a produzir conhecimento de fato.

Como já foi destacado, a relação aluno-professor não pode ser desconsiderada do processo avaliativo. As práticas avaliativas, muitas vezes intimidam os alunos, são utilizadas para aprovar ou reprovar e, não raramente, como forma de punição resultando no distanciamento entre esses agentes. As consequências da avaliação, portanto, intervêm diretamente no processo educativo e social.

Diante dos avanços sociais, tecnológicos e culturais, a escola precisa repensar sua prática e reafirmar sua existência numa sociedade em transformação. As transformações dessa sociedade proporcionam o surgimento de um novo modelo educacional, envolvido com a formação de um profissional capaz de crescer por meio das relações sociais. Nessa perspectiva, deve prevalecer uma avaliação que se preocupa com a inclusão social, com o sucesso e a permanência dos alunos nas escolas, visando a um desenvolvimento do educador e do educando, para que o aluno possa interagir e transformar a sociedade.

Dando continuidade a nossa discussão, será desenvolvida, na seção seguinte, uma crítica ao modo como é tratada a linguagem na avaliação da

Olh@res, Guarulhos, v. 2, n. 1, p. 194-221. Maio, 2014. 
pessoa com suspeita ou diagnóstico de deficiência intelectual, norteandonos por uma concepção de linguagem como forma de interação.

2. A avaliação da pessoa com suspeita ou diagnóstico de deficiência intelectual $^{3}$

A American Association on Intellectual and Developmental Disabilities (AAIDD) explica a deficiência intelectual com base em três conceitos significativos: o modelo socioecológico de deficiência, o enfoque multidimensional e a definição operativa e constitutiva da condição.

A AAIDD estabelece uma distinção entre uma definição operativa e uma definição constitutiva de deficiência intelectual. A primeira estabelece os limites do termo, separando o que está e o que não está incluído no termo, enquanto a segunda define o constructo em relação a outros constructos, estabelecendo com mais clareza os fundamentos teóricos que o definem (SCHALOCK et al., 2007). A definição toma por base três critérios a serem observados: o funcionamento intelectual, o comportamento adaptativo e a idade de início das características. Assim, conforme a AAIDD a define, "a deficiência intelectual é caracterizada por limitações significativas tanto no funcionamento intelectual, quanto no comportamento adaptativo, expresso nas capacidades adaptativas conceituais, sociais e práticas. Essa deficiência se origina antes dos 18 anos" (SCHALOCK et al., 2010, p. 1).

Essa definição deve ser observada junto a cinco premissas subjacentes, que lhe esclarecem o contexto no qual é suscitada e cuja consideração é imprescindível para adotar seu uso (SCHALOCK et al., 2007; VERDUGO \& SCHALOCK, 2010). As cinco premissas a seguir, são, portanto, essenciais para a aplicação da referida definição.

\footnotetext{
${ }^{3}$ Esta seção apresenta discussões introduzidas por Haag (2011) e desenvolvidas em Haag e Fronza (2012).
}

Olh@res, Guarulhos, v. 2, n. 1, p. 194-221. Maio, 2014. 
1. As limitações no funcionamento apresentado devem ser consideradas no contexto de ambientes comunitários típicos dos pares em idade e cultura.

2. Uma avaliação válida considera a diversidade linguística e cultural, assim como as diferenças na comunicação e nos aspectos sensoriais, motores e comportamentais.

3. Em cada indivíduo, limitações frequentemente coexistem com potencialidades.

4. Um propósito importante da descrição das limitações é desenvolver um perfil de apoios necessários.

5. Com os apoios personalizados apropriados durante um amplo período, o funcionamento da pessoa com deficiência intelectual geralmente melhorará (SCHALOCK et al., 2010, p. $1)$.

As duas primeiras premissas atentam para o sujeito sempre ser avaliado a partir de seu contexto cultural, sem levantar conclusões discriminatórias em relação a esse contexto, no que se refere a particularidades étnicas, culturais, linguísticas ou pessoais. Verdugo e Schalock (2010) chamam a atenção para o fato de que especialmente a segunda premissa pretende evitar erros historicamente cometidos na avaliação da deficiência intelectual. Portanto, não há uma relação direta entre os resultados dos testes de nível de inteligência e a deficiência intelectual (VERDUGO \& SCHALOCK, 2010). Não é difícil, não obstante essas advertências, encontrar na literatura orientações para estabelecer o diagnóstico centradas apenas na avaliação do indivíduo ou baseadas na correspondência inequívoca entre testes de inteligência e deficiência intelectual. A terceira premissa orienta a valorizar mais as potencialidades do que as dificuldades da pessoa com diagnóstico de deficiência intelectual, pois são as informações sobre as capacidades da pessoa que vão servir de base para elaborar um programa de apoio individual para o sujeito. Centrar-se nas dificuldades do indivíduo, como apontam Veltrone e Mendes (2011), dá origem a preconceitos e estereótipos de que esses sujeitos têm pouco conhecimento e, portanto, não precisam aprender tanto quanto os outros. Por fim, as duas últimas premissas determinam que o diagnóstico só tem razão de ser a fim de eleger e fornecer os apoios individualizados necessários. Conforme Verdugo \& Schalock

Olh@res, Guarulhos, v. 2, n. 1, p. 194-221. Maio, 2014. 
(2010, p. 13), "todas as pessoas têm direito à atenção e ao apoio individualizado apropriados".

O modelo socioecológico de deficiência intelectual aborda a pessoa com base na expressão de limitações no funcionamento individual dentro de um contexto social, ou seja, parece não ver a deficiência como um problema centrado na pessoa, mas como um desajuste entre as capacidades da pessoa e as demandas de seu ambiente. Por essa perspectiva, a origem da deficiência intelectual pode estar em fatores orgânicos e/ou sociais, e esses fatores "causam limitações funcionais que refletem uma falta de habilidade ou restringem tanto o funcionamento pessoal como o desempenho de papéis e de tarefas esperadas para uma pessoa em um ambiente social" 4 (VERDUGO \& SCHALOCK, 2010, p. 10). Segundo Schalock et al. (2007, p. 117), essa concepção lança o foco na interação pessoa-ambiente e reconhece que "a aplicação sistemática de apoios individualizados pode melhorar o funcionamento humano".

$O$ enfoque da AAIDD é multidimensional, porque considera o funcionamento humano por meio de cinco dimensões: habilidades intelectuais, comportamento adaptativo, saúde, participação e contexto. As habilidades intelectuais se referem às capacidades mentais gerais, que incluem raciocínio lógico, pensamento abstrato, ideias complexas, entre outras capacidades, e devem ser medidas, segundo a AAIDD, por testes padronizados. O comportamento adaptativo considera o conjunto de habilidades conceituais, sociais e práticas que o sujeito utiliza nas atividades de vida diária, e a participação consiste no desempenho da pessoa em atividades reais nos diversos âmbitos da vida social, como no trabalho, no lazer, na vida espiritual e nas atividades culturais. Ambos devem ser medidos por meio de escalas. A saúde deve ser avaliada pelo histórico de saúde do sujeito, considerando o bem-estar físico, mental e social. Sobre o contexto, por sua vez, devem ser feitas avaliações ambientais (físico, social,

\footnotetext{
${ }^{4}$ Todas as traduções do original são de inteira responsabilidade dos autores.
}

Olh@res, Guarulhos, v. 2, n. 1, p. 194-221. Maio, 2014. 
atitudinal) e pessoais (p. ex., motivação, estilos de aprendizagem, estilos de vida).

Em síntese, para se compreender a concepção de deficiência intelectual proposta pela AAIDD, que influencia os outros principais sistemas de classificação, é preciso ter em conta que ela se alicerça sobre três bases. A concepção de deficiência intelectual (i) fundamenta-se epistemologicamente no modelo socioecológico; (ii) exige uma avaliação multidimensional do sujeito; e (iii) implica uma definição com base em três critérios complementares que observam o funcionamento intelectual, o comportamento adaptativo e a idade de início das manifestações vistas como deficitárias, sendo indispensável a atenção às cinco premissas subjacentes que orientam para o fornecimento de apoios individualizados. Em outras palavras, a avaliação multidimensional se origina de um modelo socioecológico do funcionamento humano, o qual apenas é compatível com uma concepção de linguagem como forma de interação. Assim, por razões de espaço, neste trabalho, vamos verificar a adequação da avaliação de uma dessas dimensões, as habilidades intelectuais, com a concepção de linguagem que o modelo socioecológico suporta.

Pode-se dizer que a avaliação das habilidades intelectuais não apenas é a que recebe maior importância na avaliação da pessoa com suspeita de deficiência intelectual, mas também, basicamente, se constitui por meio de uma atividade de linguagem que depende da interação entre avaliador (por exemplo, um psicólogo ou um psicopedagogo) e uma pessoa com suspeita de deficiência intelectual. Nessa situação, de um lado, há um profissional com expectativa de aplicar um teste de nível de inteligência a fim de mensurar, entre outras capacidades, as de raciocínio, resolução de problemas, pensamento abstrato e compreensão de ideias complexas; de outro, há, geralmente, uma criança ou um adolescente com histórico de fracassos escolares, problemas socioambientais e baixa autoestima. Independentemente das características da pessoa em avaliação, o teste depende da atividade linguística de ambos os interlocutores, seja de

Olh@res, Guarulhos, v. 2, n. 1, p. 194-221. Maio, 2014. 
compreensão, seja de expressão. A presença da linguagem na avaliação das habilidades intelectuais é, portanto, fundamental e inquestionável.

Refletir sobre tal avaliação numa perspectiva interacionista, todavia, traz alguns problemas a serem discutidos. (1) Embora padrões numéricos ofereçam segurança para quem os manipula, a abordagem quantitativa tende a produzir um embotamento dos aspectos qualitativos que se põem em jogo. A compreensão sobre a interação, evento complexo de difícil quantificação, fica, portanto, bastante prejudicada. (2) Crer que um teste eminentemente baseado na atividade linguística possa aferir o status intelectual, por um lado, é uma hipótese ainda baseada em uma relação transparente entre pensamento e linguagem ${ }^{5}$ e, por outro, considera que a língua seja um código que transmite informações inequívocas. (3) A rigidez de um teste padronizado impede, ou pelo menos dificulta, a observação da interação no interior do teste. O profissional até poderá utilizar informações sobre a interação ocorrida durante o teste em outro instrumento, mas a influência desse episódio já terá se realizado no valor final do teste. (4) Para avaliar uma atividade de linguagem é imprescindível considerar o trabalho conjunto de construção de sentidos entre os interlocutores. Um teste de inteligência, em razão da padronização, retira da avaliação a intervenção do avaliador ao empregar o pressuposto da impessoalidade ${ }^{6}$, deixando o foco apenas no sujeito avaliado.

Assim, é perceptível certo desajuste no que concerne à concepção de linguagem que compactua com o modelo de onde se erige a explicação da deficiência intelectual segundo a AAIDD, bem como a concepção que transparece em seu modelo de avaliação e as concepções que são aceitas e empregadas nos instrumentos recomendados como adequados para aferir o status do desenvolvimento de dado indivíduo. Enquanto o modelo

\footnotetext{
${ }^{5}$ É importante aqui indicar os diferentes posicionamentos sobre o status da avaliação. A referida posição é totalmente diferente de considerar que o desenvolvimento se dá mediante a linguagem e, portanto, uma avaliação adequada das habilidades intelectuais deve compreender o funcionamento específico de linguagem do sujeito a fim de planejar um sistema de apoio individualizado.

${ }^{6}$ Por pressuposto da impessoalidade, referimo-nos à crença de que o teste revelaria resultado semelhante se aplicado por outro avaliador.
}

Olh@res, Guarulhos, v. 2, n. 1, p. 194-221. Maio, 2014. 
socioecológico do funcionamento humano apresenta uma relação estreita com uma concepção de linguagem como interação, e o modelo multidimensional de avaliação considera o funcionamento como a interação do indivíduo com seu meio, os instrumentos prestigiados embotam a presença da linguagem considerada desde um ponto de vista interacionista. Ao abrir mão de observar a forma da linguagem nos diversos âmbitos do funcionamento do indivíduo, esses instrumentos são cegos às marcas de intersubjetividade que inserem esse indivíduo na linguagem, que, por sua vez, o insere no mundo.

Na sequência, é preciso discutir de que maneira a concepção de linguagem como forma de interação interfere na reflexão sobre a definição de deficiência intelectual da AAIDD, considerando, no âmbito deste texto, as habilidades intelectuais, como já destacamos.

\section{Habilidades intelectuais e avaliação mediada pela linguagem}

Para falar sobre avaliação das habilidades intelectuais, é imprescindível, antes de tudo, posicionarmo-nos a respeito de mais alguns pontos sobre avaliação. Em primeiro lugar, vale destacar que, quando, neste trabalho, nos referimos à avaliação, o fazemos numa perspectiva diametralmente distinta da AAIDD, cujo olhar se dá no âmbito da área da Saúde. Apesar disso, a proposta aqui não é opor-se ao Manual da AAIDD, muito menos, nos limites de um artigo, propor um modelo de avaliação que o substitua. Pelo contrário, aceitando o modelo socioecológico, nossa intenção é demonstrar que uma avaliação que mantenha a coerência em relação à concepção de linguagem interacionista pode revelar aspectos do desenvolvimento da pessoa com diagnóstico de deficiência intelectual que têm sido desconsiderados pelos instrumentos validados. Esses aspectos, por sua vez, podem ser de grande importância, sobretudo para os mediadores que têm contato com crianças com esse diagnóstico. Isso significa reconhecer que a avaliação proposta pela AAIDD participa de um contexto diverso, que visa

Olh@res, Guarulhos, v. 2, n. 1, p. 194-221. Maio, 2014. 
estabelecer um diagnóstico, no sentido de definir quem apresenta e quem não apresenta deficiência intelectual.

Em segundo lugar, é necessário tornar explícitas as características que compõem esta proposta de avaliação. Assim, a finalidade desta avaliação não está em se produzir um diagnóstico como produto, que define quem apresenta ou não deficiência intelectual. Está em conhecer as características de desenvolvimento que compõem o quadro das habilidades intelectuais a fim de construir o plano de apoios adequado. Como método, esta avaliação opta pela análise qualitativa, em detrimento das prestigiadas escalas quantitativas. Uma vez que a finalidade da avaliação não passa pela rotulação de níveis, escalas ou outro sistema de classificação, não há razões para quantificar dados para análise. Quanto à metodologia, esta avaliação deve ser não padronizada, pois o foco deve estar na interação, de caráter irrepetível, e não no instrumento ou no conteúdo que produz à parte da relação entre os interlocutores. A padronização pressupõe certa universalidade na aplicação da avaliação, a qual se insensibiliza para aspectos ligados aos interlocutores e à interação propriamente dita.

A metodologia proposta aqui, entretanto, quer priorizar as práticas de linguagem desde um ponto de vista interacional a fim de compreender o desenvolvimento das habilidades intelectuais por meio da atividade de linguagem. Essa, portanto, é a última característica desta proposta. A avaliação se dirige às habilidades intelectuais manifestadas pela prática de linguagem, considerando aquelas de uma perspectiva interacionista. Tal avaliação, assim como o plano de apoios, sustenta-se na tese de Bronckart (2006, p. 10), segundo a qual "as práticas linguageiras situadas (ou os textos-discursos) são os instrumentos principais do desenvolvimento humano, tanto em relação aos conhecimentos e aos saberes quanto em relação às capacidades do agir e da identidade das pessoas”.

Conforme a AAIDD, a inteligência é uma habilidade mental geral, que inclui raciocínio, planejamento, resolução de problemas, pensamento abstrato, compreensão de ideias complexas, aprendizagem rápida e

Olh@res, Guarulhos, v. 2, n. 1, p. 194-221. Maio, 2014. 
aprendizagem a partir da experiência (SCHALOCK et al., 2010, p. 31). A avaliação dessa habilidade é feita como sendo um traço individual do sujeito, desconsiderando, portanto, os aspectos que concernem à interação. Dito de outro modo, esse tipo de avaliação tem interesse no desenvolvimento já conquistado pelo sujeito, o qual pode ser demonstrado com independência. A interação, nessa perspectiva, é vista meramente como uma espécie de "mal necessário" que tem o papel de solicitar a comprovação ou não de tais habilidades. Após essa solicitação, preferencialmente, seus vestígios são apagados, restando apenas "a resposta" do sujeito em avaliação.

É exatamente a partir da crítica a essa perspectiva que Vigotski (2010[1926]) formulou seu conceito de zona blijaichego razvitia (zona de desenvolvimento iminente ${ }^{7}$ ). O psicólogo bielo-russo observou que as avaliações de QI demonstravam apenas o desenvolvimento individual das crianças, porém, se testadas com auxílio de alguém mais experiente, essas mesmas crianças eram capazes de apresentar níveis diferentes de desenvolvimento. Vigotski (2010[1926], p. 502), então, propôs chamar de zona de desenvolvimento iminente (ZDI)

\begin{abstract}
a distância entre o nível do seu desenvolvimento atual, determinado com o auxílio de tarefas que a própria criança resolve com independência, e o nível do possível desenvolvimento, determinado com o auxílio de tarefas resolvidas sob a orientação de adultos e em colaboração com colegas mais inteligentes.
\end{abstract}

Com esse conceito, Vigotski lançou o interesse pelo desenvolvimento em maturação em detrimento da exclusividade da atenção ao desenvolvimento já maturado. Demonstrou, assim, que a interação entre os sujeitos é a força

\footnotetext{
${ }^{7} \mathrm{Na}$ cuidadosa tradução de Prestes (2010) para o conceito geralmente referido como zona de desenvolvimento proximal, a autora faz um interessante estudo sobre as traduções da obra de Vigotski no Brasil e mostra que o termo proximal se proliferou a partir da tradução norte-americana, que teria mutilado o pensamento do pensador soviético. Paulo Bezerra, tradutor das obras de Vigotski diretamente do russo, empregou o termo zona de desenvolvimento imediato. Neste trabalho, aceitamos a argumentação de Prestes (2010), uma vez que o conceito busca definir um desenvolvimento que está na iminência de ocorrer plenamente.
}

Olh@res, Guarulhos, v. 2, n. 1, p. 194-221. Maio, 2014. 
que impulsiona o desenvolvimento, uma vez que é na ZDI que ocorrem as novas aprendizagens. Para o autor soviético, o estudo da ZDI é um dos instrumentos mais poderosos de investigação do desenvolvimento infantil, cujo motivo pode ser explicado de forma simples: o mais importante "não é tanto o que a criança já aprendeu quanto o que ela é capaz de aprender" (VIGOTSKI, 2010[1926], p. 505), entendendo que o que ela é capaz de aprender deve ser compreendido como algo dinâmico, ou seja, mesmo um conhecimento cujo domínio esteja fora da ZDI, em dado momento, pode ser alcançável mais tarde.

Nesse sentido, uma avaliação das habilidades intelectuais que apresenta uma visão interacionista de linguagem deve olhar para a atividade colaborativa de linguagem que ocorre entre os interlocutores. Para estar em harmonia com o modelo socioecológico de deficiência, a avaliação deve considerar a relação entre as capacidades do sujeito e as demandas do meio em que este está inserido e não apenas as características individuais do sujeito, considerado isolado do mundo. Para estar em harmonia com o modelo socioecológico de deficiência, portanto, a avaliação deve investir em um ponto de vista positivo, apostando no estudo da ZDI, a fim de identificar o que a criança pode aprender, além do que ela já sabe, bem como tomar a linguagem numa perspectiva interacionista, pressupondo que é ela a principal responsável pelo desenvolvimento humano.

De acordo com os preceitos da educação cognitiva apresentada em Büchel (2007), acrescentamos também que tal avaliação precisa deslocar a atenção da solução encontrada para as estratégias de raciocínio, fazendo com que o sujeito (por meio da atividade de linguagem, destacamos), tome consciência do caminho que lhe serviu para resolver determinado problema intelectual. No âmbito da educação cognitiva, Büchel (2007, pp. 6-7) afirma que seu principal objetivo "é o estudo e o desenvolvimento de programas de intervenção para pessoas com dificuldades de aprendizagem e de raciocínio". Para isso, conforme o autor, enquanto numa abordagem clássica, a avaliação do sujeito se dá por meio de testes estáticos, na

Olh@res, Guarulhos, v. 2, n. 1, p. 194-221. Maio, 2014. 
abordagem da educação cognitiva, esses testes são substituídos ou pelo menos completados por testes dinâmicos. Esse é um ponto crucial para se pensar a avaliação numa perspectiva interacionista. Dito de outra forma, interessa considerar, no processo de avaliação, não apenas o produto estático das respostas dadas pela criança, mas sobretudo a dinâmica que ocorre na interação entre a criança, o mediador e a tarefa, a fim de fazer a primeira tomar consciência dos processos cognitivos que a levaram para dada resposta.

A educação cognitiva está fortemente ligada à teoria da metacognição, que, por um lado, tenta explicar os conhecimentos do indivíduo sobre seu próprio funcionamento cognitivo, sobre as especificidades de tarefas e sobre suas estratégias (metaconhecimentos) e, por outro, postula um modelo sobre o controle das atividades cognitivas (funções executivas). Büchel (2007, pp. 11-12) explica que "a reflexão metacognitiva se justifica pela possibilidade de adquirir estratégias que serão aplicáveis a um grande número de situações novas". O autor ainda defende que apenas programas de aprendizagem que se realizam por meio da reflexão metacognitiva são eficazes para o ensino de pessoas com diagnóstico de deficiência intelectual, uma vez que somente esses produzem a transferência de estratégias de resolução de problemas.

Portanto, o foco da educação cognitiva não está na solução dos problemas apresentados ao sujeito em avaliação, mas na tomada de consciência das estratégias cognitivas empregadas para encontrar tal solução, assim como na aprendizagem de novas estratégias. É fundamental destacar, nesse sentido, que tais tomadas de consciência ocorrem pela mediação realizada pelas práticas de linguagem. Eis porque assumimos com Bronckart (2006) que a linguagem é responsável pelo desenvolvimento humano.

Para Büchel (2007), a aquisição de uma estratégia cognitiva passa por três fases. Primeiramente, o aluno deve se dar conta de sua maneira de aprender e de resolver problemas. Trata-se de desautomatizar as estratégias que já emprega a fim de tomar conhecimento de seu funcionamento. Nessa fase, o

Olh@res, Guarulhos, v. 2, n. 1, p. 194-221. Maio, 2014. 
aluno deve ser confrontado com sua própria forma de pensar. Em seguida, vem a fase de aprendizagem, que pode ser demonstrada em três momentos. O aluno deve: (i) dar-se conta da utilidade de algumas estratégias que conhece, mas que não utiliza com regularidade; (ii) corrigir as estratégias antigas para torná-las mais eficazes; e (iii) aprender estratégias novas. Por fim, deve haver uma fase de exercícios para que as estratégias que foram corrigidas, assim como as recentemente aprendidas, sejam automatizadas, pois apenas dessa forma a aprendizagem se torna mais rápida e mais eficaz. Um programa de aprendizagem nessa perspectiva deve, ainda, respeitar três princípios didáticos, segundo Büchel (2007). O princípio da descoberta se sustenta no fato de que toda criança, ao longo da vida, adquire uma série de estratégias. Basta, então, em vez de ensiná-la, ajudá-la a tornar essas estratégias mais eficazes e, sobretudo, a dar-se conta da riqueza das estratégias que utiliza. O princípio da significação orienta que o mediador deve combinar previamente os objetivos da atividade a fim de que os alunos compartilhem suas metas e mantenham a atenção nelas. O princípio da alternância entre ensino frontal, trabalho em grupo e discussão em plenárias define que o ensino frontal, em que o mediador precisa explicar diretamente o conteúdo do ensino, ocupa um espaço reduzido no trabalho didático, uma vez que desfavorece a motivação. Conforme Büchel (2007, p. 22), "o mediador cria uma situação que permite aos alunos descobrirem as estratégias por eles mesmos, individualmente ou em grupo". Na discussão em plenária, o mediador dirige as atenções dos alunos principalmente para as estratégias e não para as soluções. Büchel (2007) ainda destaca a necessidade de motivar a participação de todos, no caso de as tarefas serem feitas em grupo, determinar um tempo não muito extenso para as discussões, bem como limitar o tamanho dos grupos. Para concluir, lembra que é importante apresentar por escrito uma ou duas questões bem definidas para que os alunos não percam tempo decidindo o que é para discutir.

Olh@res, Guarulhos, v. 2, n. 1, p. 194-221. Maio, 2014. 
Resta, todavia, assinalar os mecanismos linguageiros que devem constituir as interações com o aluno com diagnóstico de deficiência intelectual. Não se trata de perder de vista o foco de avaliar as habilidades intelectuais do aluno mediante suas práticas de linguagem. Trata-se antes de prever adequadamente os mecanismos interacionais de linguagem que devem estar presentes nas atividades para que haja condições adequadas para o aluno engajar-se plenamente nas tarefas e realizar as atividades com autonomia, mas de forma colaborativa. Com autonomia, haja vista a convicção de que somente o aprendizado que é autorregulado tem efeito positivo sobre o sujeito. De forma colaborativa, à medida que, conforme já amplamente referido, a interação é sempre ação entre sujeitos, e, independentemente do grau de autonomia, a colaboração constitui as práticas situadas de linguagem.

Como já evidenciamos em diversos momentos desse texto, não é possível encerrar aqui a discussão que envolve a avaliação, amparada por uma concepção de linguagem que se sustenta pela interação, de aluno com diagnóstico ou suspeita de deficiência intelectual. Cabe-nos, contudo, ressaltar que defendemos, neste trabalho, desde um ponto de vista teórico da linguagem como forma de interação, que a deficiência intelectual é uma condição que apresenta uma relação estreita com a linguagem. Propomos que a avaliação se dê considerando os aspectos ligados à interação a fim de dar suficiente visibilidade às marcas pelas quais o sujeito se inscreve na língua e, por essa via, se inscreve também no mundo. Sugerimos, ainda, que os apoios devem se dirigir não apenas ao indivíduo, mas, sobretudo, às pessoas com quem ele interage, a fim de construir uma esfera discursiva positiva no sentido de potencializar seu desenvolvimento.

Olh@res, Guarulhos, v. 2, n. 1, p. 194-221. Maio, 2014. 


\section{Considerações finais}

É evidente a necessidade de não apenas se esclarecer a concepção de linguagem que sustenta o modelo de deficiência intelectual que se postula, mas também manter a coerência com a

concepção adotada a fim de evitar que o senso comum e os preconceitos sobre a linguagem acabem servindo de baliza para a atuação dos profissionais. A AAIDD, nesse ponto, situa epistemologicamente seu modelo de explicação da deficiência intelectual desde uma visão socioecológica, definindo que a deficiência está no desajuste entre as capacidades do sujeito e as demandas do ambiente social em que este se insere. Assim, para a AAIDD, a deficiência intelectual não está no indivíduo, mas na relação deste com o meio. A concepção de linguagem que está na base deste modelo, portanto, deve ser interacionista, para que se possa, ao falar de linguagem, considerá-la na relação entre o sujeito e o seu contexto sociocultural. Não obstante, a avaliação multidimensional do funcionamento humano proposta pela AAIDD sustenta-se em testes e avaliações concebidos no âmbito de visões não interacionistas da linguagem.

Tomar a linguagem numa visão interacionista desde o modelo epistemológico até a proposta de avaliação e a definição pode significar, no contexto da deficiência intelectual, considerar essa característica de desenvolvimento não mais como um problema de saúde, mas como, simplesmente, uma característica de desenvolvimento. É evidente que as pessoas que apresentam essas características precisam de um apoio especializado, sobretudo no campo da linguagem e das interações. Todavia, vale ressaltar que a noção ainda utilizada de "limitações significativas no funcionamento intelectual" (SCHALOCK et al., 2010, p. 35) é sustentada pelo apagamento da interação e restringe a linguagem a mero instrumento de comunicação. Ou seja, ao se atribuir uma limitação ao indivíduo, de um lado, reduzem-se as expectativas pelo seu desenvolvimento futuro,

Olh@res, Guarulhos, v. 2, n. 1, p. 194-221. Maio, 2014. 
desconsiderando ou menosprezando o poder do fornecimento de apoios, de outro, imputa apenas ao indivíduo a característica de déficit, contrariando a visão socioecológica de deficiência.

Portanto, partir de uma visão interacionista da linguagem para pensar o modelo de explicação e avaliação da deficiência intelectual significa tornar a investigação sobre as práticas de linguagem o aspecto central do desenvolvimento desses indivíduos. Entretanto, essa investigação, ao se basear nas manifestações de linguagem, deve considerar a dinâmica da interação, a fim de compreender a forma específica como esses sujeitos atualizam o sistema linguístico em seus usos. Além disso, vale sublinhar que as conclusões dessa avaliação jamais podem ser imputadas ao sujeito isolado, pois nenhum sujeito emprega a linguagem no vácuo. Se a deficiência é um desajuste entre as capacidades do sujeito e as demandas de seu meio, a deficiência intelectual testemunha um desajuste entre as manifestações de linguagem de um indivíduo e o que se espera culturalmente de suas práticas de linguagem.

Nesse sentido, as reflexões sobre avaliação que aqui se fazem presentes têm o intuito também de apresentar uma alternativa para ressignificar as representações sobre a pessoa com diagnóstico de deficiência intelectual. Conforme observa Büchel (2007, p. 37), “quando os pais estão convencidos de que a desvantagem de seu filho é imutável, eles renunciam não apenas às intervenções suplementares [...], mas diminuem também as interações que teriam com uma criança sem desvantagens”. Desde Haag (2011) e Haag \& Fronza (2012), estamos chamando a essa esfera sociodiscursiva que enreda as interações do sujeito com diagnóstico de deficiência intelectual de zona de despotencialização do desenvolvimento. A partir das representações alicerçadas na ideia de "limitação cognitiva", tanto pais, quanto profissionais da saúde e da educação, assim como pares em idade ou outras pessoas, nas práticas de linguagem, restringem suas interações, despriorizando a aprendizagem da pessoa com diagnóstico de deficiência intelectual. Com isso, uma vez que o desenvolvimento humano se dá

Olh@res, Guarulhos, v. 2, n. 1, p. 194-221. Maio, 2014. 
eminentemente por meio das práticas de linguagem, na pessoa com esse diagnóstico, o desenvolvimento tende a desacelerar não apenas pelas características individuais do sujeito, mas, sobretudo, pelo abandono dos principais mediadores.

Vale destacar ainda que avaliar é um ato de reflexão profunda e constante, requer profissionais atentos às especificidades de seus alunos, que se valham de critérios coerentes e compatíveis a esses educandos, respeitando e valorizando os conhecimentos adquiridos nos diferentes níveis. É importante que a avaliação não se detenha aos aspectos comportamentais, mas evidencie o nível de conhecimento no qual o aluno se encontra, suas aprendizagens. Conviver com alunos que se distinguem do que é compreendido como um desenvolvimento esperado, permite perceber que há muito o que aprender com eles, especialmente no que diz respeito às implicações de ser diferente em uma sociedade que prima pelo normal.

Olh@res, Guarulhos, v. 2, n. 1, p. 194-221. Maio, 2014. 


\section{Referências}

ALVAREZ, A. M. M. A.; SANCHEZ, M. L.; CARVALHO, I. A. M. de. Neuroaudiologia e linguagem. In: FUENTES, D.; MALLOY-DINIZ, L. F.; CAMARGO, C. H. P..; COSENZA, R. M.. Neuropsicologia: teoria e prática. Porto Alegre: Artmed, 2008. p. 136-150.

BLOOM, B.S., HASTINGS, J.T., MADAUS, G.F. Evaluación del aprendizaje. Buenos Aires: Troquel, 1993.

BRASIL. Senado Federal. LDB: Lei de Diretrizes e Bases da Educação Nacional: Lei n. 9.394, de 1996. Brasília: Senado Federal, 1996.

BRONCKART, Jean-Paul. Atividade de linguagem, discurso e desenvolvimento humano. Campinas: Mercado de Letras, 2006.

BÜCHEL, F.. L'intervention cognitive en Éducation Spéciale: deux programmes métacognitifs. Carnet des Sciences de l'Éducation. Université de Genève. Genebra: UNIGE, 2007.

DIDÓ, A. G. . Pareceres Descritivos de alunos surdos: revelações sobre seu desempenho em língua portuguesa no ensino fundamental. Dissertação (Mestrado em Lingüística Aplicada) Universidade do Vale do Rio dos Sinos, UNISINOS, 2012.

HAAG, C. R.. A desinvenção da deficiência mental: um estudo da linguagem durante o uso de um jogo digital. Dissertação (Mestrado em Linguística Aplicada). Universidade do Vale do Rio dos Sinos. São Leopoldo: UNISINOS, 2011.

HAAG, C. R.; FRONZA, C. de A.. Da zona de desenvolvimento iminente à zona de despotencialização do desenvolvimento: representações, construção enunciativa de referentes e o diagnóstico de deficiência intelectual. Anais do I Encontro Sul Letras. São Leopoldo: UNISINOS, 2012.

HOFFMANN, J. Avaliação: mito e desafio: uma perspectiva construtivista. 19. ed. Porto Alegre: UFRGS, 1996.

LUCKESI, C. C.. Avaliação da aprendizagem na escola: reelaborando conceitos e recriando a prática. Salvador/BA: Malabares Comunicação e Eventos, 2005.

PEDROSO, F. S.; ROTTA, N. T.. Transtornos da linguagem. In: ROTTA, N. T.; OHLWEILER, L.; RIESGO, R. dos S.. (Orgs.). Transtornos da aprendizagem: abordagem neurobiológica e multidisciplinar. Porto Alegre: Artmed, 2006. p. 131-150.

PRESTES, Z. R. Quando não é quase a mesma coisa. Análise de traduções de Lev Semionovitch Vigostski no Brasil: repercussões no campo educacional. Tese (Doutorado em em Educação). Universidade de Brasília. Brasília: UnB, 2010.

SCHALOCK, Robert L.; LUCKASSON, Ruth A.; SHOGREN, Karrie A. The renaming of mental retardation: understanding the change to the term intellectual disability. Intellectual and Developmental Disabitities, vol. 45, n. 2, 2007. pp. 116-124.

SCHALOCK, R. L.; BORTHWICK-DUFFY, S. A.; BRADLEY, V.; BUNTINX, Wil H. E.; COULTER, D. L.; CRAIG, E. M.; GOMEZ, S. C.; LACHAPELLE, Y.; LUCKASSON, R.; REEVE, A.; SHOGREN, K. A.; SNELL, M. E.; SPREAT, S.; TASSÉ, M. J.; THOMPSON, J. R.; VERDUGO, M. A.; W., M. L.; YEAGER, M. H. Intellectual disability. Definition, classification, and systems of supports. 11th Edition. Washington, DC: American Association on Intellectual and Developmental Disabilities, 2010.

Olh@res, Guarulhos, v. 2, n. 1, p. 194-221. Maio, 2014. 
VASCONCELLOS, Celso dos Santos. Avaliação: concepção dialética-libertadora do processo de avaliação escolar. Cadernos Pedagógicos do Libertad. 2.ed. São Paulo: Libertad-Centro de Formação e Assessoria Pedagógica, 1992, v. 3.

VASCONCELLOS, R. Fala e escrita nas produções de uma criança com paralisia cerebral. Letras de Hoje. Porto Alegre. v. 36. n.3. p. 601-606. 2000.

VELTRONE, Aline Aparecida; MENDES, Enicéia Gonçalves. Descrição das propostas do Ministério da Educação na avaliação da deficiência intelectual. Paidéia, vol. 21, n. 50. Ribeirão Preto: FFCLRP-USP, 2011. pp. 413-421.

VERDUGO, Miguel Ángel; SCHALOCK, Robert L. Últimos avances en el enfoque y concepción de las personas con discapacidad intelectual. Siglocero: Revista Española sobre Discapacidad Intelectual, vol. 41(4), n. 236, 2010. p. 7-21.

VIGOTSKI, L. S. Psicologia pedagógica. 3. ed. São Paulo: WMF Martins Fontes, 2010[1926].

Olh@res, Guarulhos, v. 2, n. 1, p. 194-221. Maio, 2014. 